\title{
Effect of rimonabant on blood pressure in overweight/obese patients with/without co-morbidities: analysis of pooled RIO study results
}

\author{
Luis M. Ruilope ${ }^{\mathrm{a}}$, Jean-Pierre Després ${ }^{\mathrm{b}}$, André Scheen ${ }^{\mathrm{c}}$, Xavier Pi-Sunyer ${ }^{\mathrm{d}}$, Guiseppe Mancia ${ }^{\mathrm{e}}$, Alberto \\ Zanchetti $^{\mathrm{f}}$ and Luc Van Gaal ${ }^{\mathrm{g}}$
}

${ }^{\mathrm{a}}$ Hypertension Unit, Hospital 12 de Octubre, Madrid, Spain, ${ }^{\mathrm{b}}$ Quebec Heart Institute, Laval Hospital Research Center, Laval University, Sainte-Foy, Quebec, Canada, ${ }^{c}$ Division of Diabetes, Nutrition, and Metabolic Disorders, CHU Sart Tilman, University of Liege, Liege, Belgium, ${ }^{d}$ St Luke's-Roosevelt Hospital Center, New York, New York, USA, ${ }^{e}$ Policlinico di Monza, Istituo di Medicina Cardiovascolare, Univerità di Milano, Milan, ${ }^{\mathrm{f}}$ Instituto Auxologico Italiano, Milan, Italy and ${ }^{9}$ Department of Diabetology, Metabolism, and Clinical Nutrition, University Hospital Antwerp, Antwerp, Belgium

\begin{abstract}
Objective: Rimonabant, the first selective cannabinoid type $1\left(\mathrm{CB}_{1}\right)$ receptor blocker, has been shown to improve multiple cardiometabolic risk factors in overweight/obese patients. This analysis assessed the impact of rimonabant on blood pressure in the pooled population from four large trials with similar design - the Rimonabant-In-Obesity (RIO) programme.
\end{abstract}

Methods: RIO-Europe $(n=1507)$ and RIO-North America $(n=3040)$ recruited overweight/obese patients, and RIO-Lipids $(n=1033)$ and RIO-Diabetes $(n=1045)$ recruited overweight/obese patients with untreated dyslipidaemia or type 2 diabetes, respectively. At study entry (screening), 37.2\% $(n=2463)$ of patients had hypertension, $71.4 \%(n=1757)$ of whom were taking an antihypertensive treatment.

Results: After 1 year of treatment, mean change in systolic blood pressure (SBP) from baseline was $-0.8 \mathrm{mmHg}$ for rimonabant $20 \mathrm{mg}$ versus $+0.3 \mathrm{mmHg}$ for placebo $(P=0.007)$; diastolic blood pressure (DBP) decreased by 0.8 versus $-0.3 \mathrm{mmHg}(P=0.029)$ respectively. In the subgroup of patients with high blood pressure at baseline, SBP change was $-7.5 \mathrm{mmHg}$ for rimonabant $20 \mathrm{mg}$ versus $-4.7 \mathrm{mmHg}$ for placebo $(P=0.005)$; DBP change was -5.2 versus $-3.0 \mathrm{mmHg}(\mathrm{P}<0.001)$. Reductions were more pronounced in patients with dyslipidaemia and type 2 diabetes. There was no effect of rimonabant $20 \mathrm{mg}$ on blood pressure beyond that expected from weight loss alone. Overall, there was a similar incidence of adverse events (AEs) at 1 year in the placebo $(81.8 \%)$ and rimonabant $20 \mathrm{mg}(86.0 \%)$. The most common AEs occurring with rimonabant were nausea, dizziness, arthralgia and diarrhoea. A slightly higher proportion of patients in the rimonabant $20 \mathrm{mg}$ group discontinued as a result of AEs (13.8\%) versus placebo (7.2\%).

Conclusions: Rimonabant $20 \mathrm{mg}$ led to modest, but significant SBP and DBP reductions in overweight/obese patients. The effect of rimonabant on blood pressure appears to be mediated by weight loss.

Keywords: blood pressure, diabetes, dyslipidaemia, overweight/obesity, rimonabant, risk factor

Abbreviations: ANCOVA, analysis of co-variance; BMI, body mass index; $\mathrm{CB}_{1}$, cannabinoid type 1 receptor; CHD, coronary heart disease; DBP, diastolic blood pressure; ECS, endocannabinoid system; HDL-C, high density lipoprotein-cholesterol; ITT, intention to treat; RIO, Rimonabant in Obesity; SBP, systolic blood pressure; SHR, spontaneously hypertensive rats; TG, triglycerides

\section{INTRODUCTION}

Although the awareness and treatment of hypertension has increased in recent years, blood pressure control remains suboptimal with only $36.8 \%$ of hypertensive patients achieving treatment goals [1]. Hypertension is a key risk factor for cardiovascular disease, contributing to the increased prevalence of cardiovascular events [2]; reducing blood pressure by an average of $12 / 6 \mathrm{mmHg}$ has been shown to reduce stroke by $40 \%$ and coronary heart disease by $20 \%$ [3]. The absolute risk reduction will be greatest in those at highest risk, such as patients with type 2 diabetes. Results from the United Kingdom Prospective Diabetes Study (UKPDS) indicated that a 
reduction of elevated blood pressure might decrease cardiovascular disease morbidity and mortality even more than reduction of hyperglycaemia [4].

The link between obesity (particularly abdominal obesity) and hypertension and other cardiometabolic risk factors is well established [5-9]. Indeed, data from the Framingham Heart Study estimate that 75 and $65 \%$ of the cases of hypertension in men and women, respectively, are directly attributable to overweight and obesity [10]. The attributable risk of hypertension induced by abdominal obesity has been estimated to range from 21 to $57 \%$, depending on gender and ethnicity [11]. Body weight change itself is a potent modulator of hypertension risk: in the Nurses Health Study after adjusting for body mass index, weight gain in adulthood of as little as 2.1-4.9 kg increased the risk of hypertension by $29 \%$, whereas weight loss of $5 \mathrm{~kg}$ was associated with a $15 \%$ reduction in hypertension risk [12]. A meta-analysis of randomized, controlled trials showed that weight loss is important for the prevention and treatment of hypertension: blood pressure reductions were $-1.05 \mathrm{mmHg}$ for SBP and -0.92 $\mathrm{mmHg}$ for DBP when expressed per kilogram of weight loss [13]. While short-term interventions to produce weight loss effectively lower blood pressure, long-term maintenance of a reduced body weight is a difficult objective to achieve. Pharmacotherapy can facilitate sustained weight loss and can benefit some patients; however, some weight-loss agents may increase or prevent the weight-loss-induced reduction in blood pressure [14].

The recently discovered endocannabinoid system (ECS) plays a role in energy balance, and glucose and lipid metabolism through central and peripheral actions $[15,16]$. Recently, an association between the overactiva-tion of the ECS, the abdominal obesity phenotype characterized by high visceral or intra-abdominal fat, and the different cardiometabolic risk factors has been described [17-19]. While this association with abdominal obesity suggests that the overactive ECS is a potential target for addressing blood pressure, current evidence indicates that in rodent models of hypertension, inhibition of the overactive ECS using cannabinoid type 1 receptor $\left(\mathrm{CB}_{1}\right)$ blockade evoked further sustained increases in blood pressure [20].

Rimonabant, the first selective $\mathrm{CB}_{1}$ receptor blocker, has been shown to improve multiple cardiometabolic risk factors, such as abdominal obesity, dyslipidaemia, glycae-mic control and insulin resistance in overweight/obese patients [21-24]. About 50\% of the effects of rimonabant on lipid and glycaemic variables has been shown to be independent of weight loss and may reflect direct metabolic effects of $\mathrm{CB}_{1}$ blockade in peripheral tissues [15$17,25]$.

The aim of this exploratory analysis was to investigate a possible effect on blood pressure of $\mathrm{CB}_{1}$ blockade by assessing the impact of rimonabant on blood pressure in overweight/obese patients with dyslipidaemia, type 2 diabetes and high blood pressure (SBP $\geq 130 \mathrm{mmHg}$ and/or DBP $\geq 85 \mathrm{mmHg}$ in patients with type 2 diabetes and SBP $\geq 140 \mathrm{mmHg}$ and/or DBP $\geq 90 \mathrm{mmHg}$ in patients without diabetes) using pooled and individual study data from the four large Rimonabant-In-Obesity (RIO) multicentre, randomized controlled trials.

\section{METHODS}

\section{Overview of the RIO programme}

The RIO (Rimonabant in Obesity and Related Metabolic Disorders) trial programme included four Phase III, multinational, multicentre, randomized, double-blind, placebo-controlled, fixed-dose studies in overweight/ obese patients [body mass index $\left.(\mathrm{BMI})>27 \mathrm{~kg} / \mathrm{m}^{2}\right]$ [21-24]. RIO-North America $(n=3040)$ and RIO-Europe $(n=$ $1507)$ included patients with or without dyslipidaemia, RIO-Lipids $\left(n=1033\right.$; BMI $\left.27-40 \mathrm{~kg} / \mathrm{m}^{2}\right)$ included patients with untreated dyslipidaemia, and RIO-Diabetes $\left(n=1040\right.$; BMI $\left.27-40 \mathrm{~kg} / \mathrm{m}^{2}\right)$ included patients with type 2 diabetes receiving metformin or sulfonylureas. All studies included patients with or without hypertension.

\section{Study design}

The study design for Year 1 was identical in the four studies. The protocol and patient inclusion/exclusion criteria have been described in detail [21-24]. Briefly, after a 2-week screening period a mildly hypocaloric diet $(600 \mathrm{kcal} /$ day deficit) was prescribed for all patients, starting with a 4-week single-blind placebo run-in period. Thereafter, patients had their baseline evaluation and were then randomized to placebo, rimonabant $5 \mathrm{mg} / \mathrm{day}$ or rimonabant $20 \mathrm{mg} /$ day while continuing the hypocaloric diet (600 kcal reduction) and were encouraged to increase physical activity. Patients were allocated to treatment using an Interactive Voice Responding System (IVRS) (central randomization) ensuring that the study participants, treatment providers and sponsor did not have access to the treatment assignments for each randomization code. The primary endpoint of the trials was mean change in body weight from baseline at 1 year, with secondary endpoints including a range of 
cardiometabolic risk factors, such as waist circumference, haemoglobin $\mathrm{A}_{\mathrm{lc}}\left(\mathrm{Hb}_{\mathrm{lc}}\right)$, high-density lipoprotein cholesterol (HDL-C) and triglyceride (TG) levels, plasma glucose and insulin levels, and blood pressure. Specifically, supine systolic (SBP) and diastolic blood pressure (DBP) were exploratory secondary endpoints in the RIO trials in addition to being a measure of clinical safety.

Blood pressure was measured in agreement with the existing Committee for Proprietary Medicinal Products (CPMP) guidelines [26]. Readings were taken in the supine position using a calibrated mercury sphygmomanometer and an appropriately sized cuff. At the screening visit, two consecutive readings separated by 2 min were taken in both arms. The arm with the higher pressure was determined and this arm was used for the measurement of blood pressure throughout the study. Two readings of supine blood pressure separated by 2 min were then recorded at every patient visit under standardized conditions, approximately at the same time each day, on the same arm, by the same person and with the same apparatus. Hypertension was defined in the protocol as $\mathrm{SBP} \geq 130 \mathrm{mmHg}$ and/or $\mathrm{DBP} \geq 85 \mathrm{mmHg}$ in patients with type 2 diabetes, and $\mathrm{SBP} \geq 140 \mathrm{mmHg}$ and/or $\mathrm{DBP} \geq 90 \mathrm{mmHg}$ in patients without diabetes, or the presence of antihypertensive therapy if blood pressure was below these limits; patient hypertension status was recorded at the screening visit. This exploratory analysis used the above SBP and DBP cut-off points to identify patients with high blood pressure at baseline.

The RIO study protocols were approved by the institutional review board/ethics committee for each participating centre. The study was conducted in full compliance with the Declaration of Helsinki.

\section{Statistical analysis}

The effects of rimonabant 5 and $20 \mathrm{mg}$ /day treatment on blood pressure over 1 year were evaluated in the four individual studies and in the pooled studies data. In the individual trials, the $5 \mathrm{mg}$ dose did not consistently produce clinically relevant improvements in body weight or lipid and glycaemic parameters [21-24].

Accordingly, only the rimonabant $20 \mathrm{mg}$ dose (the dose approved commercially in Europe) and placebo were presented in these analyses. The effects of treatment on the change from baseline in blood pressure and the other efficacy endpoints were assessed using analysis of variance. Placebo-adjusted effects of rimonabant were assessed as the least-squares (LS) mean difference. Blood pressure changes were also analysed in patients with high blood pressure at baseline from the following populations of the studies: pooled across the four RIO trials; those with untreated dyslipidaemia [21]; and those with type 2 diabetes [23]. All analyses were applied to the modified intent-to-treat population, defined as all patients who were randomized, exposed to at least one dose of study drug and had at least one post-baseline assessment. Missing data at study endpoint were imputed using the last observation carried forward method.

Differences between treatment arms in changes in anti-hypertension medications were analysed using a chisquared test to compare the frequency distribution of patients in each treatment group who had an upward adjustment, downward adjustment, no change or change to another drug due to insufficient efficacy, or another reason during the treatment period.

An analysis of the direct effect of rimonabant on blood pressure was conducted in order to provide a quantitative assessment of the degree to which blood pressure changes at 1 year might be mediated by direct effects of the treatment. The model was based on a standard regression method in which body weight loss was introduced as a post-randomization covariate [analysis of covariance (ANCOVA)]. To assess any weight-independent effect of rimonabant on a given variable, the portion of the effect of rimonabant that was due to body weight change was removed from the total effect on the variable. The ANCOVA model introduced treatment group and body weight change as a covariate. The methodology for this analysis has also been described elsewhere $[21,22]$.

\section{RESULTS}

The pooled 1-year intent-to-treat population consisted of 1602 patients and 2503 patients randomized to placebo and rimonabant $20 \mathrm{mg}$, respectively. Characteristics of the patients in each of the individual RIO studies have been published previously [21-24]; all four studies pooled are summarized in Table 1. Overall, the RIO studies represent an at-risk population of overweight/ obese patients with an elevated waist circumference (86-97\%) and a high rate of cardiometabolic risk factors. In total, $37 \%$ of the pooled population had previously diagnosed hypertension, comprising $61 \%$ of patients in RIO-Diabetes (BP $\geq 130 / 85 \mathrm{mmHg}$ ) and 27\% of RIO-Lipids and $30-41 \%$ of RIO-North America and RIO-Europe (BP $\geq 140 / 90 \mathrm{mmHg}$ ). Of the patients previously diagnosed with hypertension, $71 \%$ of the pooled patients were receiving antihypertensive medication. The percentage of the overall patient population from the four individual RIO trials receiving antihypertensive medications were: angiotensin-converting enzyme inhibitors 11.6-12.7\%; angiotensin II receptor blockers 5.2-6.2\%; beta- 
adrenergic receptor blockers 8.4-8.5\%; calcium-channel blockers 6.3-6.5\%; and diuretics 7.7-9.9\%. During the treatment period most patients had no changes in antihypertensive medications (approximately 94\% of patients) and the distribution of changes in antihypertensive medication was not significantly different in the two treatment arms. In the placebo and rimonabant $20 \mathrm{mg}$ groups, 3.8 versus $2.7 \%$ required upward dose changes; 1.3 versus $2.0 \%$ required downward dose changes; and 0.4 versus $0.3 \%$ of patients had medication changes due to insufficient efficacy over 1 year.

Table 1 Patient overall demographic and baseline characteristics

\begin{tabular}{ll}
\hline & Pooled studies $^{\mathrm{a}}(\mathrm{n}=6625)$ \\
\hline Age (years) & $47.1(11.6)$ \\
Gender $(\%)$ & 27.4 \\
Male & 72.6 \\
Female & \\
Race $(\%)$ & 88.9 \\
Caucasian & 7.1 \\
Black & 4.0 \\
Other & $100.8(19.5)$ \\
Weight $(\mathrm{kg})$ & $106.8(13.9)$ \\
Waist circumference $(\mathrm{cm})$ & $36.0(5.8)$ \\
Body mass index $\left(\mathrm{kg} / \mathrm{m}^{2}\right)$ & 37.2 \\
Hypertension $(\%)^{\mathrm{b}}$ & 71.4 \\
Drug treatment if hypertensive $(\%)$ & \\
Abdominal obesity $(\%)$ & 85.5 \\
$\quad$ Male (waist circumference $>102 \mathrm{~cm})$ & 90.5 \\
Female (waist circumference $>88 \mathrm{~cm})$ & 66.9 \\
Dyslipidaemia $(\%)^{\mathrm{c}}$ & 17.8 \\
Drug treatment if dyslipidaemic $(\%)$ & 15.8 \\
Type 2 diabetes $(\%)^{\mathrm{d}}$ & 46.5 \\
Metabolic syndrome $(\%)^{\mathrm{e}}$ &
\end{tabular}

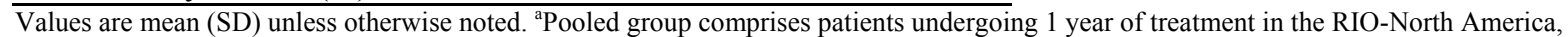
RIO-Europe, RIO-Lipids and RIO-Diabetes studies. ${ }^{b}$ Hypertension: defined as systolic blood pressure (SBP) $\geq 140 \mathrm{mmHg}$ and/or diastolic blood pressure (DBP) $\geq 90 \mathrm{mmHg}$ in patients without type 2 diabetes, and SBP $\geq 130 \mathrm{mmHg}$ and/or DBP $\geq 85 \mathrm{mmHg}$ in patients with type 2 diabetes, or antihypertension treatment, as per protocol. ${ }^{\circ}$ Dyslipidaemia: defined as triglyceride levels $\geq 1.69 \mathrm{mmol}(150 \mathrm{mg} / \mathrm{dl}) \mathrm{and} / \mathrm{or}$ total cholesterol/high-density lipoprotein cholesterol (HDL-C) ratio $>4.5$ in women or $>5$ in men, as per protocol. ${ }^{\mathrm{d}}$ Type 2 diabetes: haemoglobin $\mathrm{A}_{1 \mathrm{c}} 6.5-10.0 \%$ and fasting glucose concentration 5.55-15.04 mmol/1, as per protocol. ${ }^{\mathrm{e}}$ Percentage of patients meeting the criteria for metabolic syndrome (ATP III), defined as at least three of the following: abdominal obesity (waist circumference) $>102 \mathrm{~cm}$ for men and $>$ $88 \mathrm{~cm}$ for women; triglycerides level $\geq 1.695 \mathrm{mmol}(150 \mathrm{mg} / \mathrm{dl})$; HDL-C level $<1.036 \mathrm{mmol}(40 \mathrm{mg} / \mathrm{dl})$ for $\mathrm{men}$ and $<1.295 \mathrm{mmol}(50 \mathrm{mg} / \mathrm{dl})$ forwomen; $\mathrm{SBP} \geq 130 \mathrm{mmHg}$ or $\mathrm{DBP} \geq 85 \mathrm{mmHg}$; and fasting glucose level $>6.1 \mathrm{mmol}(110 \mathrm{mg} / \mathrm{dl})$.

\section{Overall pooled population (four RIO studies)}

In the overall population during the run-in period (before randomization to placebo or rimonabant treatment), there was a substantial mean (SD) decrease in SBP [-2.9 (11.3) $\mathrm{mmHg}$ ] and DBP [-1.3 (7.8) $\mathrm{mmHg}$ (Table 2a). This decrease was even more marked in those patients with high blood pressure at the beginning of the placebo run-in period ( $\mathrm{SBP} \geq 130 \mathrm{mmHg}$ and/or DBP $\geq 85 \mathrm{mmHg}$ in patients with type 2 diabetes and $\mathrm{SBP} \geq 140 \mathrm{mmHg}$ and/or DBP $\geq 90 \mathrm{mmHg}$ in patients without diabetes): SBP -7.4 (11.9) $\mathrm{mmHg}$ and DBP -3.7 (8.0) $\mathrm{mmHg}$ (Table 2a). During the run-in period, body weight and waist circumference decreased by $-1.8(2.1) \mathrm{kg}$ and $-1.9(3.8) \mathrm{cm}$, respectively, in the overall pooled population, and by $-2.0(2.1) \mathrm{kg}$ and $-1.8(3.6) \mathrm{cm}$, respectively, in the subgroup with high blood pressure at baseline.

The effect of 1 year of treatment with rimonabant $20 \mathrm{mg}$ /day on blood pressure in the pooled ITT population is shown in Table $2 \mathrm{~b}$ and Fig. 1. In the overall population (Fig. la), changes in SBP and DBP from baseline were statistically significant between rimonabant $20 \mathrm{mg}$ /day and placebo groups $(P=0.007$ and $P=0.029$, versus placebo, respectively). In patients with high blood pressure at baseline (Fig. lb), mean changes in SBP and DBP were more pronounced, with significant reductions in SBP and DBP in the rimonabant $20 \mathrm{mg} /$ day group versus placebo $(P=0.005$ and $P<0.001$, respectively $)$.

Body weight loss and the reductions in waist circumference at 1 year were also significantly greater in the rimonabant $20 \mathrm{mg}$ group compared with placebo. In the overall pooled ITT population receiving rimonabant 20 
$\mathrm{mg}$ /day, mean weight loss from baseline at 1 year was $-6.3(6.8) \mathrm{kg}(P<0.001$ versus placebo). A similar reduction in body weight was reported in patients with high blood pressure at baseline: $-6.6(6.7) \mathrm{kg}(P<0.001$ versus placebo). Rimonabant $20 \mathrm{mg}$ /day also evoked similar reductions in waist circumference in the pooled ITT patients $[-6.2(7.0) \mathrm{cm}]$ and in those with high blood pressure at baseline $[-6.3(7.2) \mathrm{cm}]$, both $P<0.001$ versus placebo. As previously reported in the individual RIO studies [21-24], significantly greater improvements were also observed in the rimonabant $20 \mathrm{mg}$ groups compared with placebo in $\mathrm{HbA}_{\mathrm{lc}}$, fasting plasma glucose and insulin levels, HDL-C and TG.

\section{Relationship between blood pressure changes and weight loss}

Regression lines from the ANGOVA model showing the changes in SBP or DBP regressed on the change in body weight from baseline in the overall population and in patients with high blood pressure for the rimonabant $20 \mathrm{mg}$ /day and placebo groups were virtually identical (Fig. 2a and b). As expected, there was a strong linear relationship between degree of weight loss and blood pressure reductions; however, this relationship was similar in the two treatment arms. After adjusting the observed changes in blood pressure for weight changes in the analysis of covariance, the residual treatment effect on blood pressure was not significant. Thus, the effect of rimonabant $20 \mathrm{mg} /$ day is consistent with that seen for placebo in patients matched for the same degree of weight loss. This suggests that rimonabant $20 \mathrm{mg}$ /day does not have an additional effect on blood pressure beyond that attributable to weight loss.

Table 2 Change in blood pressure during run-in (a) and after 1 year (b) (four pooled studies ${ }^{a}$ )

(a) Change in blood pressure during placebo run-in period at screening (4 weeks; ITT population)

\begin{tabular}{|c|c|c|c|c|}
\hline & \multicolumn{2}{|c|}{$\begin{array}{l}\text { Overall population } \\
\quad n=6625\end{array}$} & \multicolumn{2}{|c|}{$\begin{array}{l}\text { High blood pressure }{ }^{\mathrm{b}} \text { at screening } \\
\qquad n=1987\end{array}$} \\
\hline \multicolumn{5}{|l|}{ Supine SBP (mmHg) } \\
\hline Start of run-in & \multicolumn{2}{|c|}{$127.5(13.9)$} & \multicolumn{2}{|l|}{$142.5(9.5)$} \\
\hline End of run-in & \multicolumn{2}{|c|}{$124.6(13.5)$} & \multicolumn{2}{|l|}{$135.1(12.3)$} \\
\hline Change & \multicolumn{2}{|c|}{$-2.9(11.3)$} & \multicolumn{2}{|l|}{$-7.4(11.9)$} \\
\hline \multicolumn{5}{|l|}{ Supine DBP (mmHg) } \\
\hline Start of run-in & \multicolumn{2}{|c|}{$79.8(8.7)$} & \multicolumn{2}{|l|}{$87.0(7.8)$} \\
\hline End of run-in & \multicolumn{2}{|c|}{$78.5(8.3)$} & \multicolumn{2}{|l|}{83.3 (7.9) } \\
\hline Change & \multicolumn{2}{|c|}{$-1.3(7.8)$} & \multicolumn{2}{|l|}{$-3.7(8.0)$} \\
\hline \multicolumn{5}{|c|}{ (b) Change in blood pressure after 1 year (ITT population, LOCF) } \\
\hline & \multicolumn{2}{|c|}{ Overall population } & \multicolumn{2}{|c|}{ High blood pressure $^{\mathrm{b}}$ at baseline } \\
\hline & $\begin{array}{l}\text { Placebo } \\
n=1570\end{array}$ & $\begin{array}{c}\text { Rimonabant } 20 \mathrm{mg} \\
n=2466\end{array}$ & $\begin{array}{l}\text { Placebo } \\
n=396\end{array}$ & $\begin{array}{c}\text { Rimonabant } 20 \mathrm{mg} \\
n=526\end{array}$ \\
\hline \multicolumn{5}{|l|}{ Supine SBP (mmHg) } \\
\hline Mean baseline (SD) & $124.7(13.4)$ & $124.6(13.4)$ & $140.7(9.3)$ & $141.7(9.8)$ \\
\hline Year 1 & $125.0(13.8)$ & $123.8(13.6)$ & $136.0(13.5)$ & $134.3(13.0)$ \\
\hline Mean change from baseline (SD) & $0.3(12.0)$ & $-0.8(12.4)$ & $-4.7(13.2)$ & $-7.5(13.2)$ \\
\hline LS Mean change versus placebo (SE) & - & $-1.1(0.4)$ & - & $-2.5(0.9)$ \\
\hline$P$ value (20 mg versus placebo) & & $(P=0.007)$ & & $(P=0.005)$ \\
\hline \multicolumn{5}{|l|}{ Supine DBP (mmHg) } \\
\hline Mean baseline (SD) & $78.6(8.1)$ & $78.4(8.3)$ & $85.5(7.4)$ & $86.5(7.6)$ \\
\hline Year 1 & $78.3(8.4)$ & $77.5(8.2)$ & $82.5(8.7)$ & $81.3(8.0)$ \\
\hline Mean change from baseline (SD) & $-0.3(8.2)$ & $-0.8(8.4)$ & $-3.0(8.8)$ & $-5.2(8.1)$ \\
\hline LS Mean change versus placebo (SE) & - & $-0.6(0.3)$ & - & $-2.0(0.6)$ \\
\hline$P$ value (20 mg versus placebo) & & $(P=0.029)$ & & $(P<0.001)$ \\
\hline
\end{tabular}

DBP, diastolic blood pressure; ITT, intention-to-treat; LOCF, last observation carried forward; LS, least squares; SBP, systolic blood

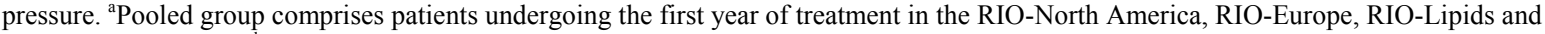
RIO-Diabetes studies. ${ }^{b} \mathrm{BP} \geq 140 / 90 \mathrm{mmHg}$ (RIO-North America, RIO-Europe and RIO-Lipids) or $\geq 130 / 85 \mathrm{mmHg}$ (RIO-Diabetes). 
(a) Overall patient population
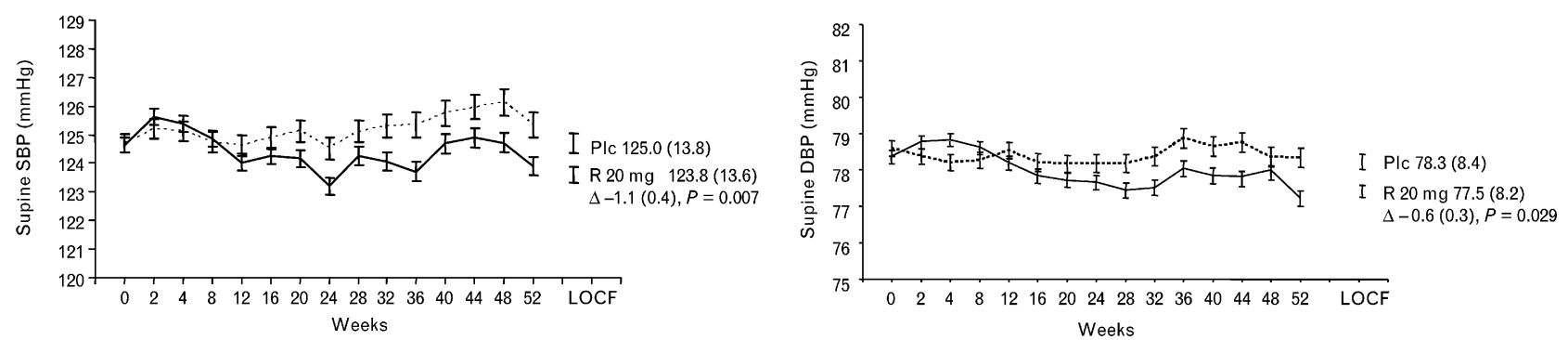

(b) Patients with high blood pressure at baseline
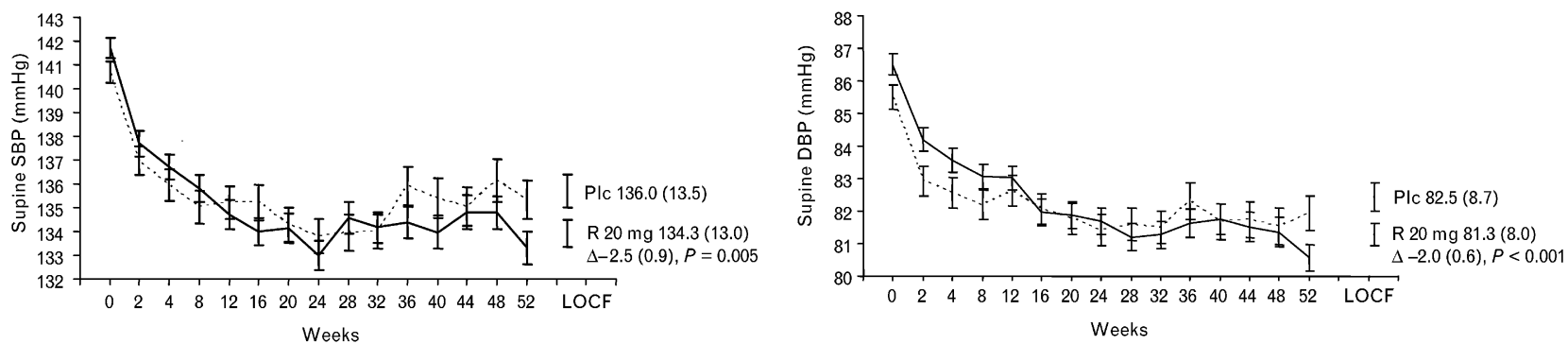

(a) Systolic blood pressure (SBP) (left panel) and diastolic blood pressure (DBP) (right panel) over 1 year in the overall intention-to-treat (ITT) population from the four pooled Rimonabant In Obesity (RIO) studies. Data are means (SEM) ( $P$ versus placebo), (b) SBP (left panel) and DBP (right panel) over 1 year in patients with high blood pressure at baseline in the four pooled RIO studies (high blood pressure defined as $\mathrm{SBP} \geq 140 \mathrm{mmHg}$ and/or $\mathrm{DBP} \geq 90 \mathrm{mmHg}$ in patients without type 2 diabetes and $\mathrm{SBP} \geq 130 \mathrm{mmHg}$ and/or DBP $\geq 85 \mathrm{mmHg}$ in patients with type 2 diabetes). LOCF (last observation carried forward): mean (SD). Dotted lines, placebo; solid lines rimonabant 20mg.

\section{Patients with type 2 diabetes (RIO-Diabetes)}

Of the patients with type 2 diabetes previously diagnosed with hypertension at screening in the RIO-Diabetes trial, 93\% of these were receiving antihypertensive drug treatment, compared with only 55-69\% in the other RIO studies. In the overall patient population from the RIO-Diabetes trial, changes in SBP and DBP overall were small but greater in the rimonabant $20 \mathrm{mg}$ group compared with placebo $(P=0.02$ and $P=0.06$ versus placebo, respectively; Fig. 3a). In patients with both type 2 diabetes and high blood pressure (SBP $\geq 130 \mathrm{mmHg}$ and/or $\mathrm{DBP} \geq 85 \mathrm{mmHg}$ ) at baseline, mean reductions from baseline in both SBP and DBP were more pronounced than in the overall trial population and were significantly greater in the rimonabant $20 \mathrm{mg} /$ day group than the placebo group $(P=0.013$ and $P=0.024$ versus placebo) (Fig. 3b).

\section{Patients with untreated dyslipidaemia (RIO-Lipids)}

In patients with untreated atherogenic dyslipidaemia, the mean reductions from baseline in SBP and DBP were significantly greater in the rimonabant $20 \mathrm{mg}$ /day group than the placebo group $\mathrm{CP}<0.05$ ), for both the overall population (Fig. 4a) and for patients with high blood pressure at baseline (SBP $\geq 140 \mathrm{mmHg}$ and/or DBP $\geq 90$ mmHg) (Fig. 4b).

The safety and tolerability of rimonabant $20 \mathrm{mg}$ has been reported previously in the individual studies [21-24]; pooled safety results are presented in Table 3. Briefly, rimonabant $20 \mathrm{mg}$ was generally well tolerated, with the safety data consistent in different subpopulations; the most common adverse events, occurring in at least 5\% of patients and more commonly with rimonabant $20 \mathrm{mg}$ than placebo, were upper respiratory tract infection, nausea, influenza, dizziness, diarrhoea, asthenia/fatigue, anxiety and insomnia. The percentage of patients experiencing adverse events which led to study discontinuation was similar in both the overall patient population and those patients wit high blood pressure at baseline (Table 3a). Specifically, adverse events leading to study discontinuation in the overall population occurred in 7.2 and $13.8 \%$ of patients in the placebo and rimonabant 20 $\mathrm{mg}$ groups, respectively, in year 1 , the most common of which are listed in Table $3 \mathrm{~b}$. 
Fig. 2

(a)

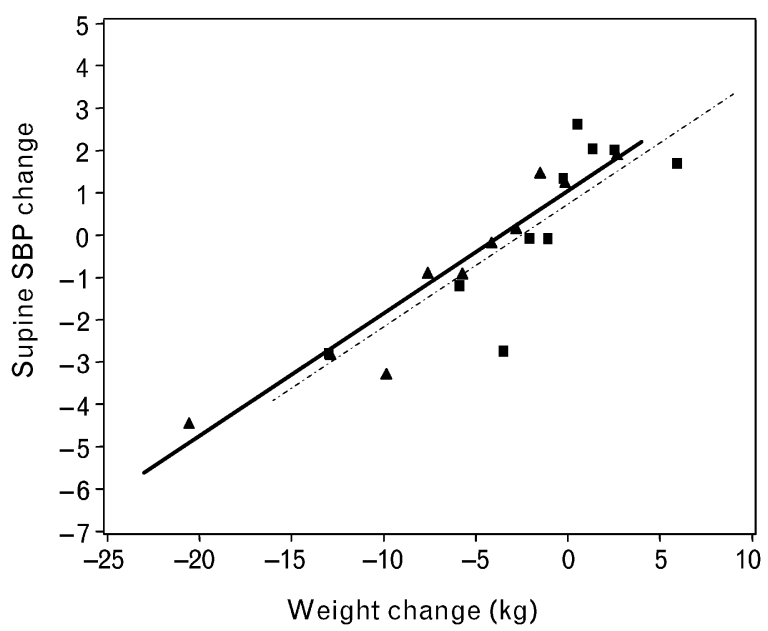

(b) Patients with high blood pressure at baseline

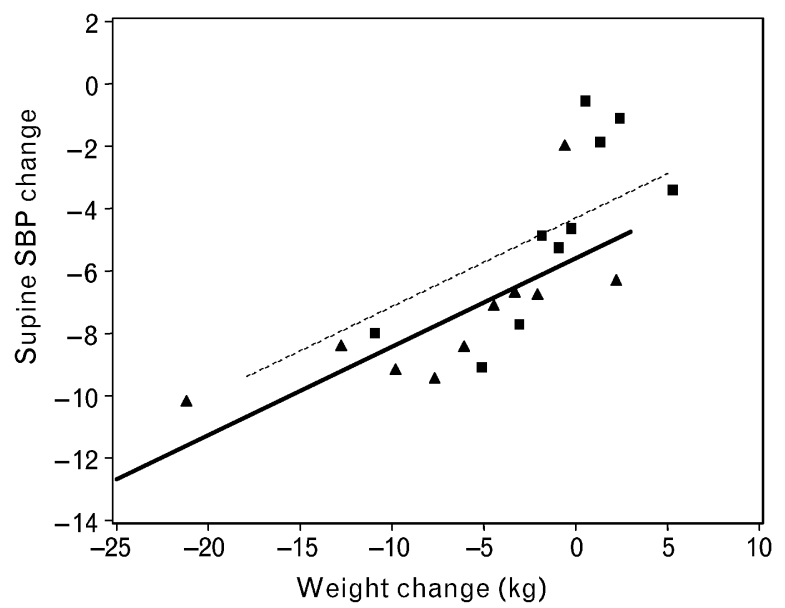

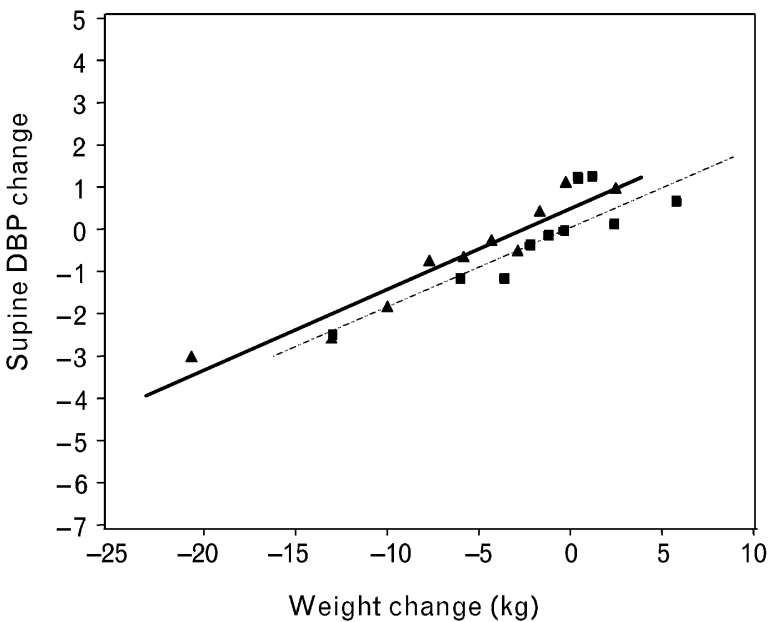

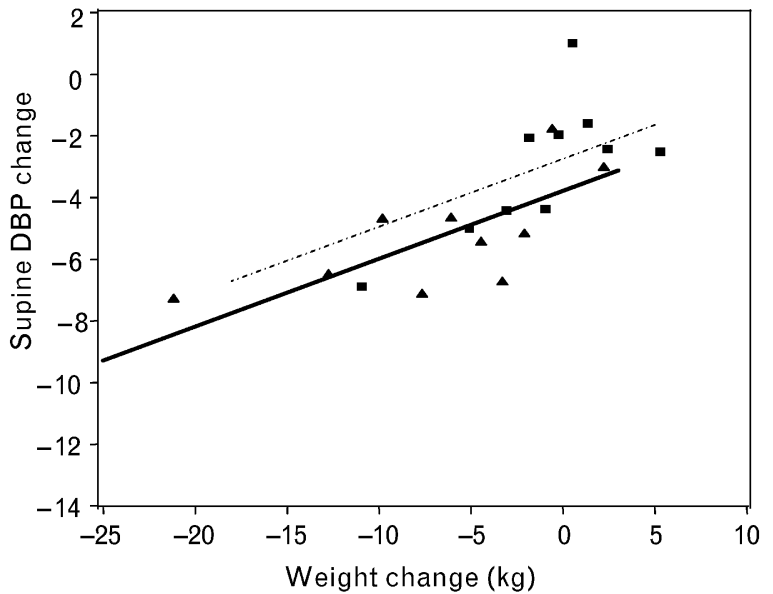

(a) Analysis of covariance: relationship between change in weight from baseline and change in systolic blood pressure (SBP) (left panel) and diastolic blood pressure (DBP) (right panel) at 1 year in the overall intention-to-treat (ITT) population from the four pooled RIO studies. For graphical display purposes, patients in each treatment group were divided according to decile of weight change, and mean change in blood pressure and weight were calculated for each decile. Results are presented as mean (SEM) for the ITT population, (b) Analysis of covariance: relationship between change in weight from baseline and change in SBP (left panel) and DBP (right panel) at 1 year in patients with high blood pressure at baseline in the four pooled RIO studies (high blood pressure defined as SBP $\geq 140 \mathrm{mmHg}$ and/or DBP $\geq 90 \mathrm{mmHg}$ in patients without type 2 diabetes and SBP $\geq 130 \mathrm{mmHg}$ and/or DBP $\geq 85 \mathrm{mmHg}$ in patients with type 2 diabetes). Dotted lines and solid squares, placebo; solid lines and solid triangles rimonabant $20 \mathrm{mg}$.

\section{DISCUSSION}

In the individual RIO trials and the pooled data, small but consistent decreases in both SBP and DBP were observed following 1 year of treatment with rimonabant $20 \mathrm{mg}$ /day. This relatively small reduction was observed despite normal mean blood pressure at baseline; however, in the subset of patients with elevated blood pressure at baseline, more pronounced reductions in both SBP and DBP were noted and both were reduced significantly more by rimonabant $20 \mathrm{mg}$ compared with placebo treatment. It is also relevant to note that the total blood pressure-lowering effect does not include the 1-4 mmHg reductions in blood pressure observed during the 4week run-in period in these trials. These results are consistent with the blood pressure reductions observed in hypertension prevention trials in patients with normal or high blood pressure [13]. Current clinical evidence indicates that blood pressure elevation above optimal levels (i.e. $>115 / 75 \mathrm{mmHg}$ ) will increase an individual's risk of developing cardiovascular diseases [2,27]. Thus, even small reductions in blood pressure from above optimal levels should impart a health benefit, especially in the overweight/obese population [28]. 
(a) Overall population with type 2 diabetes at baseline
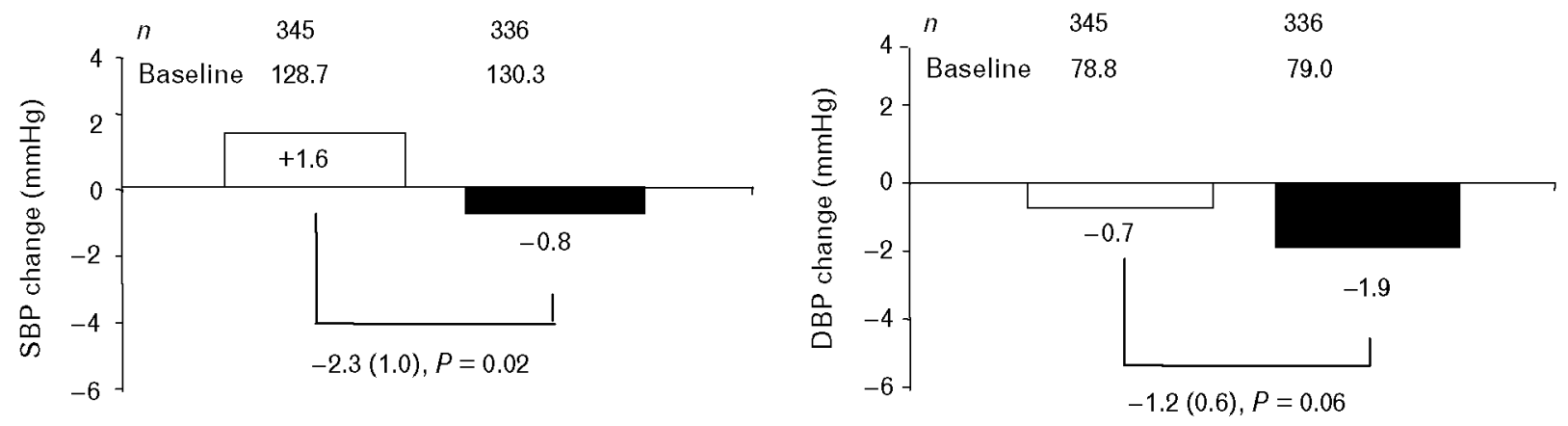

(b) Patients with type 2 diabetes and high blood pressure at baseline
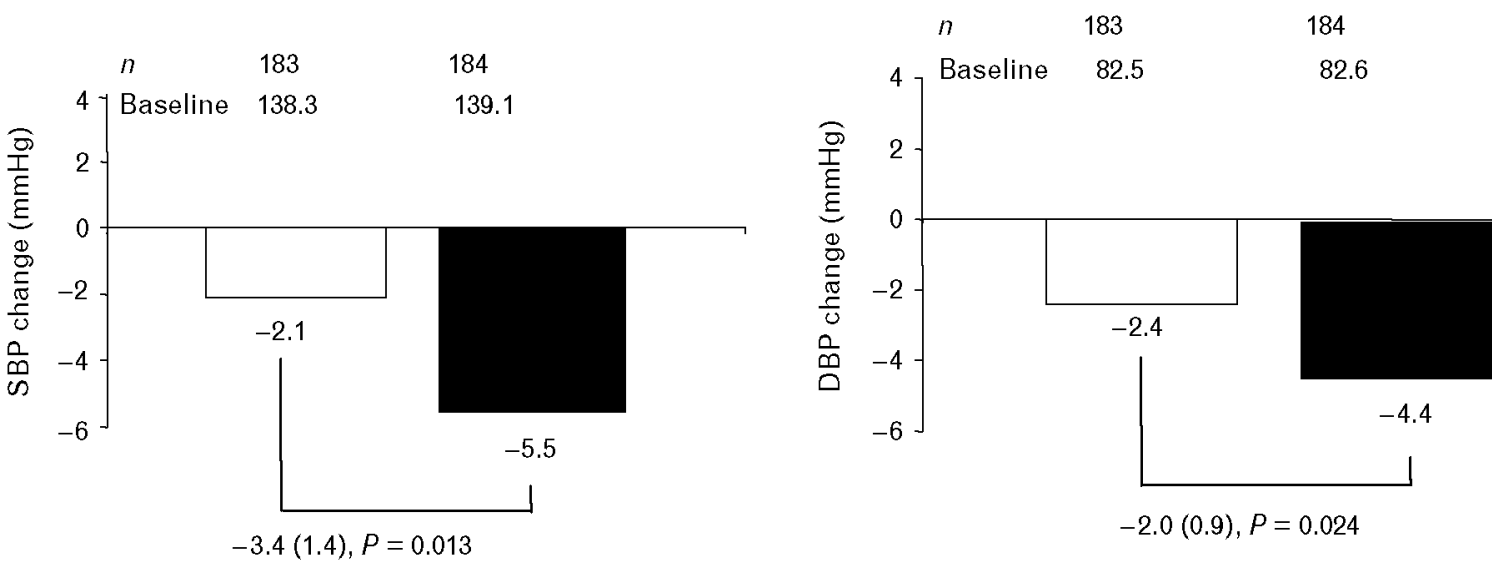

(a) Changes in systolic blood pressure (SBP) (left panel) and diastolic blood pressure (DBP) (right panel) at 1 year in the subset of patients with type 2 diabetes at baseline. Data are means from the intention-to-treat (ITT) population. Between-group comparisons are least-squares mean differences (SEM) (P versus placebo), (b) Changes in SBP (left panel) and DBP (right panel) at 1 year in the subset of patients with type 2 diabetes and high blood pressure at baseline (high blood pressure defined as SBP $\geq 130 \mathrm{mmHg}$ and/or DBP $\geq 85 \mathrm{mmHg}$ in patients with type 2 diabetes). Type 2 diabetes (RIO-Diabetes) defined as haemoglobin $\mathrm{A}_{1 \mathrm{c}} 6.5-10.0 \%$ and fasting glucose concentration $5.55-15.04$ $\mathrm{mmol} / \mathrm{l}$, as per protocol. White bars, placebo; black bars rimonabant $20 \mathrm{mg}$.

Among the individual trials, the reductions in blood pressure were somewhat more evident in the studies which specifically enrolled patients at higher cardiometabolic risk (e.g. patients with dyslipidaemia or type 2 diabetes). The small antihypertensive effect in the overall patient population adds to the other, previously reported, cardiometabolic benefits of rimonabant; namely, reduced body weight and waist circumference, improved lipid profile (higher HDL-C and lower TG), reduced C-reactive protein and improved glycaemic control [21-24]. Since risk factors tend to cluster within individuals, improvements in multiple inter-related parameters is a reasonable approach to reducing overall cardiometabolic risk [29].

Cardiovascular outcomes trials of antihypertension therapy have established that small differences in systolic blood pressure reductions $(2-4 \mathrm{mmHg})$ are associated with large reductions $(10-20 \%)$ in major cardiovascular events [3]. It is also interesting to note that in the Anglo-Scandinavian Cardiac Outcomes Trial (ASCOT), for example, in which two antihypertensive regimens were compared (amlodipine plus perindopril as required versus atenolol plus bendroflumethiazide and potassium as required), differential systolic reductions in SBP and DBP of 2.8 and $1.9 \mathrm{mmHg}$, respectively, were associated with a $14 \%$ reduction in risk of fatal coronary heart disease (GHD), non-fatal myocardial infarction and coronary revascularizations [30]. Moreover, further analyses of these trial results indicated that blood pressure differences alone could not account for differences in outcomes, and that small beneficial effects on other risk factors, including HDL-G, TG, $\mathrm{HbA}_{\mathrm{lc}}$ and fasting blood glucose appeared to contribute to the reduced risk in coronary events [30].

The effect of rimonabant $20 \mathrm{mg} /$ day on blood pressure seems to be mediated by weight loss, with rimonabant having no apparent direct effect on blood pressure at the dose of $20 \mathrm{mg}$ /day beyond that attributable to weight 
loss. In contrast, approximately half of the improvements in $\mathrm{HDL}-\mathrm{C}, \mathrm{TG}$ and $\mathrm{HbA}_{\mathrm{lc}}$ levels produced by rimonabant therapy over 1 year were beyond those expected by weight loss alone, as reported previously [2124].

Fig. 4

(a) Overall population with dyslipidaemia at baseline
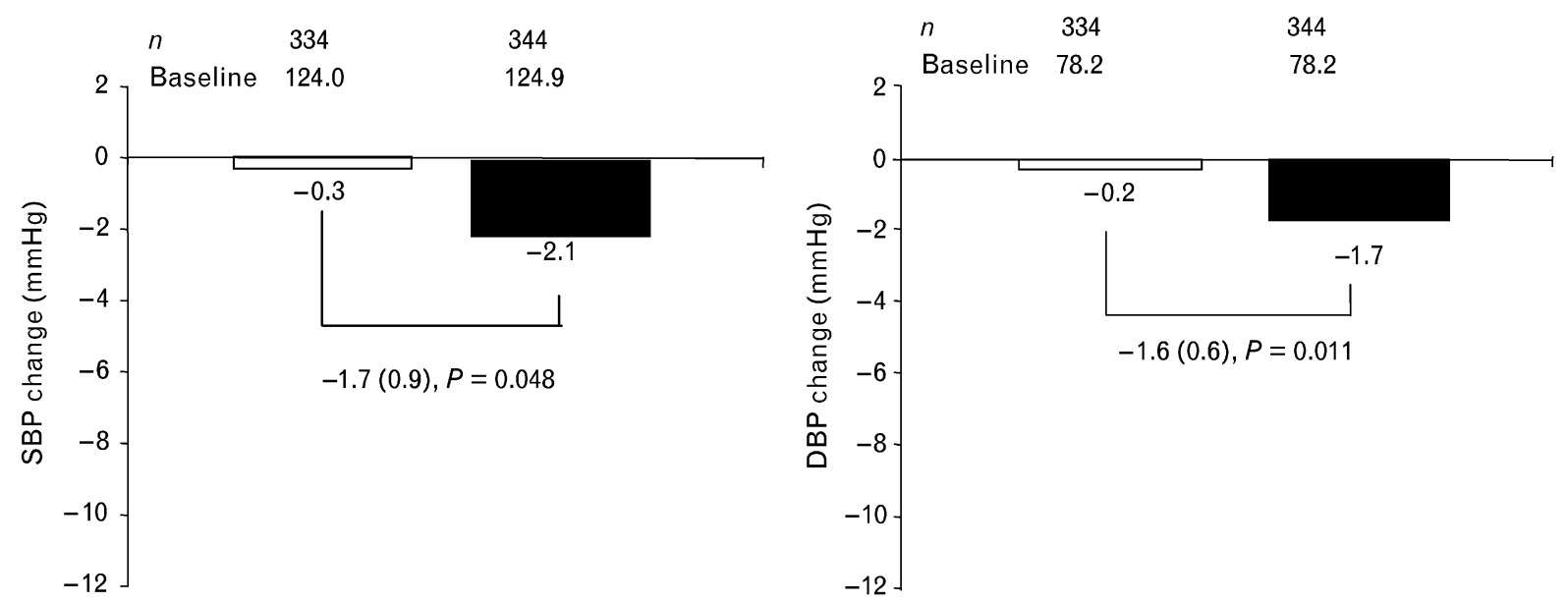

(b) Patients with dyslipidaemia and high blood pressure at baseline
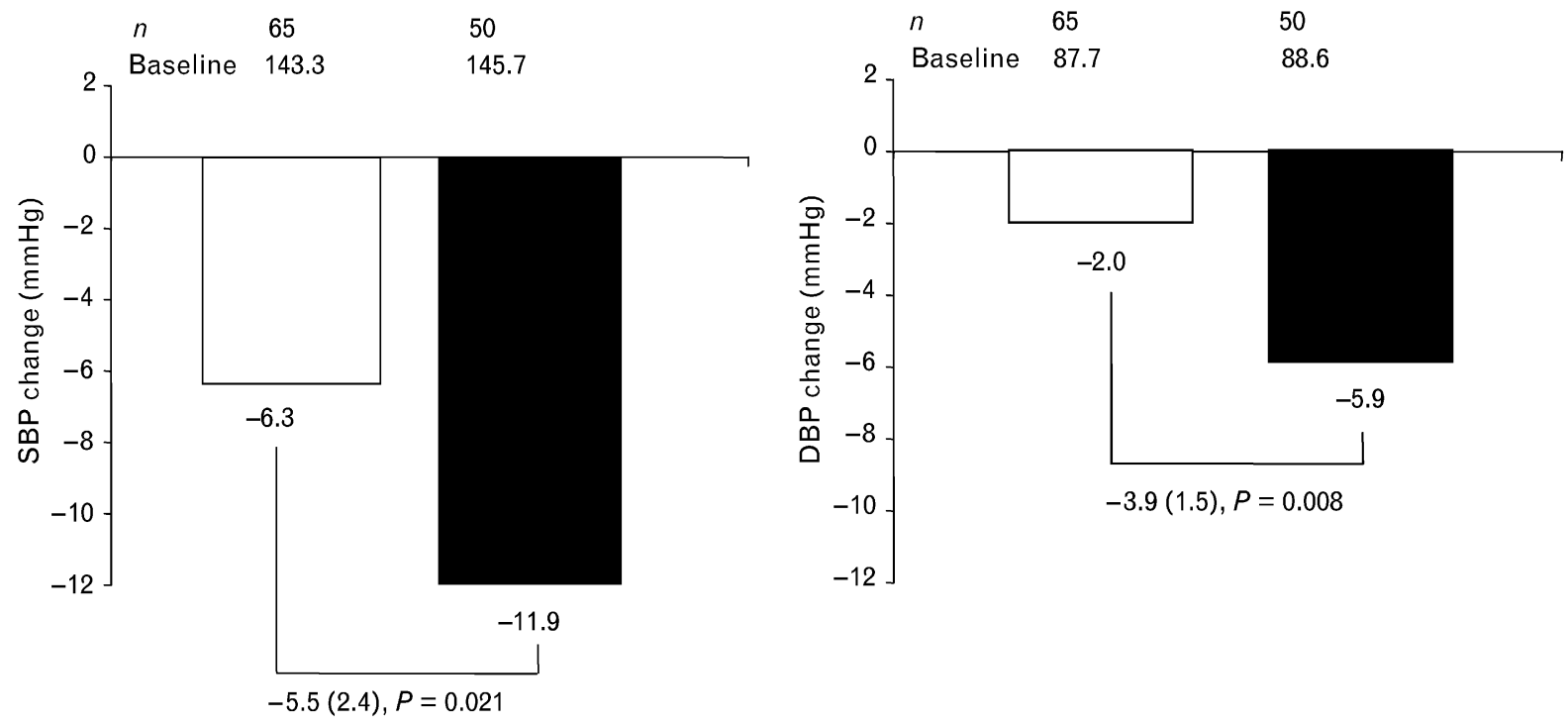

(a) Changes in systolic blood pressure (SBP) (left panel) and diastolic blood pressure (DBP) (right panel) at 1 year in the subset of patients with untreated dyslipidaemia at baseline. Data are means from the intention-to-treat (ITT) population. Between-group comparisons are leastsquares mean differences (SEM) ( $P$ versus placebo), (b) Changes in SBP (left panel) and DBP (right panel) at 1 year in the subset of patients with untreated dyslipidaemia and high blood pressure at baseline (high blood pressure defined as SBP $\geq 140 \mathrm{mmHg}$ and/or DBP $\geq 90 \mathrm{mmHg}$ ). Dyslipidaemia defined as triglyceride levels $\geq 1.69 \mathrm{mmol}(150 \mathrm{mg} / \mathrm{dl})$ and/or total cholesterol/high-density lipoprotein cholesterol (HDL-C) ratio $>4.5$ in women or $>5$ in men, as per protocol. White bars, placebo; black bars rimonabant $20 \mathrm{mg}$. 
Table 3 Safety

(a) Summary of adverse events at 1 year (pooled data from four RIO studies)

\begin{tabular}{|c|c|c|}
\hline & Placebo $[n(\%)]$ & Rimonabant $20 \mathrm{mg}[n(\%)]$ \\
\hline Overall patient population & 1602 & 2503 \\
\hline Patients with any adverse event & $1310(81.8)$ & $2152(86.0)$ \\
\hline Patients with diabetes, any adverse event ${ }^{\mathrm{a}}$ & $276 / 348(79.3)$ & $288 / 339(85.0)$ \\
\hline Patients with dyslipidaemia, any adverse event ${ }^{\mathrm{b}}$ & $279 / 342(81.6)$ & $300 / 346(86.7)$ \\
\hline Patients $\geq 65$ years old, any adverse event & $87 / 105(82.9)$ & $145 / 170(85.3)$ \\
\hline Men, any adverse event & $380 / 477(79.7)$ & $542 / 652(83.1)$ \\
\hline Women, any adverse event & $930 / 1125(82.7)$ & $1610 / 1851(87.0)$ \\
\hline Patients with any serious adverse event & $67(4.2)$ & $148(5.9)$ \\
\hline Discontinuations due to adverse events & $115(7.2)$ & $346(13.8)$ \\
\hline Patients with high blood pressure at baseline ${ }^{c}$ & 401 & 532 \\
\hline Patients with any adverse event & $319(79.6)$ & $461(86.7)$ \\
\hline Patients with any serious adverse event & $18(4.5)$ & $41(7.7)$ \\
\hline Discontinuations due to adverse events & $29(7.2)$ & $70(13.2)$ \\
\hline
\end{tabular}

(b) Most common adverse events that led to discontinuation ${ }^{d}$

\begin{tabular}{|c|c|c|}
\hline & Placebo $[n(\%)]$ & Rimonabant $20 \mathrm{mg}[n(\%)]$ \\
\hline Patient population & 1602 & 2503 \\
\hline Any class, any event & $115(7.2)$ & $346(13.8)$ \\
\hline Depressive disorders* & $13(0.8)$ & $48(1.9)$ \\
\hline Nausea & $2(0.1)$ & $34(1.4)$ \\
\hline Mood alterations with depressive symptoms** & $9(0.6)$ & $26(1.0)$ \\
\hline Anxiety & $5(0.3)$ & $26(1.0)$ \\
\hline Dizziness & $1(<0.1)$ & $17(0.7)$ \\
\hline Pregnancy & $0(0)$ & $5(0.5)$ \\
\hline
\end{tabular}

(c) Adverse events (by system organ class and preferred term) occurring in $\geq 2 \%$ of patients in the rimonabant $20 \mathrm{mg}$ group and by $\geq 1 \%$ compared with patients in the placebo group

\begin{tabular}{|c|c|c|}
\hline & Placebo $[n(\%)]$ & Rimonabant $20 \mathrm{mg}[n(\%)]$ \\
\hline Patient population & 1602 & 2503 \\
\hline Gastrointestinal disorders & $419(26.2)$ & $761(30.4)$ \\
\hline Nausea & $79(4.9)$ & $299(11.9)$ \\
\hline Diarrhoea & $77(4.8)$ & $157(6.3)$ \\
\hline Vomiting & $36(2.2)$ & $100(4.0)$ \\
\hline Nervous system disorders & $360(22.5)$ & $643(25.7)$ \\
\hline Dizziness & $79(4.9)$ & $187(7.5)$ \\
\hline Hypoaesthia & $9(0.6)$ & $40(1.6)$ \\
\hline Psychiatric disorders & $217(13.5)$ & $622(24.9)$ \\
\hline Anxiety & $39(2.4)$ & $140(5.6)$ \\
\hline Insomnia & $51(3.2)$ & $134(5.4)$ \\
\hline Mood alterations with depressive symptoms & $49(3.1)$ & $119(4.8)$ \\
\hline Depressive disorders & $25(1.6)$ & $79(3.2)$ \\
\hline Irritability & $9(0.6)$ & $48(1.9)$ \\
\hline Nervousness & $4(0.2)$ & $29(1.2)$ \\
\hline \multicolumn{3}{|l|}{ Miscellaneous } \\
\hline Upper respiratory tract infection & $182(11.4)$ & $311(12.4)$ \\
\hline Asthenia/fatigue & $80(5.0)$ & $151(6.0)$ \\
\hline Contusion & $10(0.6)$ & $54(2.2)$ \\
\hline Tendonitis & $16(1.0)$ & $52(2.1)$ \\
\hline Hot flush & $12(0.7)$ & $47(1.9)$ \\
\hline
\end{tabular}


It is difficult to separate the effect of weight loss itself from concomitant benefits of weight loss, such as reductions in visceral fat, hyperinsulinaemia and insulin resistance [7,8], all of which may contribute to the observed blood pressure-lowering effect of rimonabant therapy. Substantial evidence implicates visceral obesity in the pathophysiology of obesity-related hypertension [5,31]. The visceral adipose tissue is an intriguing potential site for the effects of $\mathrm{CB}_{1}$ blockade, as recent studies in humans have shown increased $\mathrm{CB}_{1}$ receptor expression in visceral compared with subcutaneous adipose tissue, and higher endocannabinoid levels in obese patients with a predominance of visceral compared with subcutaneous excess adipose tissue [18,19]. In the RIO trials, reductions in abdominal obesity (as measured by waist circumference) paralleled body weight loss [2124].

Preclinical studies have shown that endogenous canna-binoids exert a hypotensive effect, particularly in rodent models of hypertension or under conditions of endotoxic or haemorrhagic shock [20,32]. $\mathrm{CB}_{1}$ agonists lower blood pressure much more in spontaneously hypertensive rats (SHR) than in normotensive Wistar-Kyoto rats, while $\mathrm{CB}_{1}$ blockade prevented this effect in SHR but had no effect on blood pressure in normotensive rats. These results suggest a role of the ECS in the regulation of blood pressure; however, it is important to note that the blood pressure-lowering effect of endocannabinoids in these hypertensive animal models is accounted for primarily by tonic suppression of cardiac contractility in hypertension, and that a pressor effect of $\mathrm{CB}_{1}$ blockade has only been noted in animal models of hypertension with supraphysiological doses and in anaesthetized but not conscious animals [20]. There is no evidence of any pressor effect of rimonabant in any clinical studies. Our data demonstrate that rimonabant treatment does not counteract the favourable effects of weight loss and of mobilization of abdominal fat on blood pressure in overweight/obese humans [13]. On the contrary, the RIO clinical data showed reductions in blood pressure with rimonabant therapy, which are more pronounced in patients with high blood pressure at baseline.

There are several limitations in these analyses of the effects of rimonabant on blood pressure. First, the studies were not specifically designed to evaluate the effect of rimonabant in hypertension. For this reason, more rigorous methods for assessing blood pressure, such as use of an automated blood pressure recording system or ambulatory blood pressure measurements, were not employed. Second, both body weight and blood pressure decreased during the 4-week dietary run-in period; thus, the changes from randomization do not fully capture the total effects that may be seen in clinical practice. Large, randomized, controlled trials specifically designed to evaluate cardiovascular outcomes of long-term rimonabant therapy are currently ongoing.

In summary, the results of this analysis demonstrate that treatment with rimonabant at $20 \mathrm{mg} /$ day can lower the blood pressure of overweight/obese patients in addition to its effect on other cardiometabolic risk factors such as abdominal obesity, dyslipidaemia, inflammation, dysgly-caemia and insulin resistance. While the overall blood pressure-lowering effect of rimonabant was relatively small and was entirely attributable to the concomitant body weight loss, there was no evidence of blood pressure increases with rimonabant treatment. In patients with high blood pressure at baseline, improvements in SBP and DBP were more pronounced than in the overall pooled population. Taken collectively, the effects on blood pressure, plus the previously demonstrated improvements in lipid profile, glycaemic control and abdominal obesity, support the use of selective $\mathrm{CB}_{1}$ blockade with rimonabant as a novel approach to the management of multiple cardiometabolic risk factors.

\section{Acknowledgements}

The RIO programme was sponsored by Sanofi Synthe-labo Research, a division of Sanofi Synthelabo Inc., a member of the Sanofi-Aventis group. Editorial support for this article was provided by Sanofi Synthelabo Research. Conflict of interest: Luis Ruilope has served as an adviser and speaker for Sanofi-Aventis.

\section{References}

1 Ong KL, Cheung BM, Man YB, Lau CP, Lam KS. Prevalence, awareness, treatment, and control of hypertension among United States adults 1 999-2004. Hypertension 2007; 49:69-75.

2 Lewington S, Clarke R, Qizilbash N, Peto R, Collins R. Age-specific relevance of usual blood pressure to vascular mortality: a meta-analysis of individual data for one million adults in 61 prospective studies. Lancet 2002; 360:1903-1913. 
3 Turnbull F. Effects of different blood-pressure-lowering regimens on major cardiovascular events: results of prospectively-designed overviews of randomised trials. Lancet 2003; 362:1527-1535.

4 Adler AI, Stratton IM, Neil HA, Yudkin JS, Matthews DR, Cull CA, et al. Association of systolic blood pressure with macrovascular and microvascular complications of type 2 diabetes (UKPDS 36): prospective observational study. BMJ 2000; 321:41 2-419.

5 Davy KP, Hall JE. Obesity and hypertension: two epidemics or one? Am J Physiol Regul Integr Comp Physiol 2004; 286:R803-R813.

6 Janssen I, Katzmarzyk PT, Ross R. Waist circumference and not body mass index explains obesity-related health risk. Am J Clin Nutr 2004; 79:379-384.

7 Despres J-P, Lemieux I. Abdominal obesity and metabolic syndrome. Nature 2006; 444:881 -887.

8 Van Gaal L, Mertens IL, De Block CE. Mechanisms linking obesity with cardiovascular disease. Nature 2006; 444:875-880.

9 Jordan J, Engeli S, Redon J. European Society of Hypertension Working Group on Obesity: background, aims and perspectives. $J$ Hypertens 2007; 25:897-900.

10 Garrison R, Kannel W, Stokes J, Castelli W. Incidence and precursors of hypertension in young adults: the Framingham Off-spring Study. Prev Med 1987; 16:235-251.

11 Okosun IS, Prewitt TE, Cooper RS. Abdominal obesity in the United States: prevalence and attributable risk of hypertension. J Hum Hypertens 1 999; 13:425-430.

12 Huang Z, Willett WC, Manson JE, Rosner B, Stampfer MJ, Speizer FE, Colditz GA. Body weight, weight change, and risk for hypertension in women. Ann Intern Med 1 998; 128:81 -88.

13 Neter JE, Stam BE, Kok FJ, Grobbee DE, Geleijnse JM. Influence of weight reduction on blood pressure: a meta-analysis of randomized controlled trials. Hypertension 2003; 42:878-884.

14 Kim SH, Lee YM, Jee SH, Nam CM. Effect of sibutramine on weight loss and blood pressure: a metaanalysis of controlled trials. Obes Res 2003; 11:1116-1123.

15 Osei-Hyiaman D, DePetrillo M, Pacher P, Liu J, Radaeva S, Batkai S, et al. Endocannabinoid activation at hepatic CB1 receptors stimulates fatty acid synthesis and contributes to diet-induced obesity. J Clin Invest 2005; 115:1298-1305.

16 Cota D, Marsicano G, Tschop M, Grubler Y, Flachskamm C, Schubert M, et al. The endogenous cannabinoid system affects energy balance via central orexigenic drive and peripheral lipogenesis. J Clin Invest $2003 ; 112: 423-431$.

17 Matias I, Gonthier MP, Orlando P, Martiadis V, De Petrocellis L, Cervino C, et al. Regulation, function, and dysregulation of endocannabinoids in models of adipose and beta-pancreatic cells and in obesity and hyperglycemia. J Clin Endocrinol Metab 2006; 91:31 71 -3180.

18 Blüher M, Engeli S, Kloting N, Berndt J, Fasshauer M, Batkai S, et ai. Dysregulation of the peripheral and adipose tissue endocannabinoid system in human abdominal obesity. Diabetes 2006; 55:3053-3060.

19 Cote M, Matias I, Lemieux I, Petrosino S, Aimeras N, Després J-P, Di Marzo V. Circulating endocannabinoid levels, abdominal adiposity and related cardiometabolic risk factors in obese men. Int J Obes 2007; 31:692-699.

20 Batkai S, Pacher P, Osei-Hyiaman D, Radaeva S, Liu J, Harvey-White J, et al, Endocannabinoids acting at cannabinoid-1 receptors regulate cardiovascular function in hypertension. Circulation 2004; 110:1996-2002.

21 Despres J-P, Golay A, Sjostrom L, the Rimonabant in Obesity-Lipids Study Group. Effects of rimonabant on metabolic risk factors in overweight patients with dyslipidemia. N Engl J Med 2005; 353:2121-2134. 
22 Pi-Sunyer FX, Aronne U, Heshmati HM, Devin J, Rosenstock J. Effect of rimonabant, a cannabinoid-1 receptor blocker, on weight and cardiometabolic risk factors in overweight or obese patients: RIO-North America: a randomized controlled trial. JAMA 2006; 295:761 -775.

23 Scheen AJ, Finer N, Hollander P, Jensen MD, Van Gaal L, for the RIO-Diabetes Study Group. Efficacy and tolerability of rimonabant in overweight or obese patients with type 2 diabetes: a randomised controlled study. Lancet 2006; 368:1 660-1 672.

24 Van Gaal LF, Rissanen AM, Scheen AJ, Ziegler O, Rossner S. Effects of the cannabinoid-1 receptor blocker rimonabant on weight reduction and cardiovascular risk factors in overweight patients: 1-year experience from the RIO-Europe study. Lancet 2005; 365:1389-1397.

25 Engeli S, Bohnke J, Feldpausch M, Gorzelniak K, Janke J, Batkai S, et al. Activation of the peripheral endocannabinoid system in human obesity. Diabetes 2005; 54:2838-2843.

26 European Agency for the Evaluation of Medicinal Products. CPMP note for guidance on clinical investigation of medicinal products in the treatment of hypertension. EMEA; 1998.

27 Chobanian AV, Bakris GL, Black HR, Cushman WC, Green LA, Izzo JL Jr, et al. The Seventh Report of the Joint National Committee on Prevention, Detection, Evaluation, and Treatment of High Blood Pressure: the JNC 7 report. JAMA 2003; 289:2560-2572.

28 Klein S, Burke LE, Bray GA, Blair S, Allison DB, Pi-Sunyer FX, et al. Clinical implication of obesity with specific focus on cardiovascular disease: a statement for professionals from the American Heart Association Council on Nutrition, Physical Activity and Metabolism: endorsed by the American College of Cardiology Foundation. Circulation 2004; 110:2952-2967.

29 Gaede P, Vedel P, Larsen N, Jensen GV, Parving HH, Pedersen O. Multifactorial intervention and cardiovascular disease in patients with type 2 diabetes. N Engl J Med 2003; 348:383-393.

30 Poulter NR, Wedel H, Dahlöf B, Sever PS, Beevers DG, Caulfield M, et al. Role of blood pressure and other variables in the differential cardiovascular event rates noted in the Anglo-Scandinavian Cardiac Outcomes Trial-Blood Pressure Lowering Arm (ASCOT-BPLA). Lancet 2005; 366:907-913.

31 Ahmed MH. Rimonabant as a potential new treatment for an emerging epidemic of obesity-related glomerulopathy? Expert Opin Emerging Drugs 2006; 11:563-565.

32 Wagner JA, Jarai Z, Batkai S, Kunos G. Hemodynamic effects of cannabinoids: coronary and cerebral vasodilation mediated bycannabinoid CB(1) receptors. Eur J Pharmacol 2001 ; 423:203-210. 